\title{
Kombinasi penggunaan quadhelix dan tanggul gigitan posterior pada perawatan crossbite anterior
}

\author{
Rhabiah El Fithriyah
}

IImu Kesehatan Gigi Anak, Program Studi Kedokteran Gigi, Fakultas Kedokteran, Universitas Jenderal Achmad Yani, Jawa Barat, Indonesia

Jl Terusan Jendral Sudirman, Cimahi, Jawa Barat, Indonesia; e-mail: devirhabiah@gmail.com

\begin{abstract}
ABSTRAK
Perawatan crossbite anterior dapat dilakukan dengan beberapa macam alat baik dengan alat lepasan ataupun alat cekat. Salah satu alat semi cekat yang dapat digunakan pada perawatan crossbite anterior adalah quad helix dengan kombinasi tanggul gigitan posterior. Quad helix merupakan alat yang dapat digunakan untuk konstriksi dental di maksila pada masa remaja. Seorang pasien anak perempuan berusia 11 tahun mengeluhkan keadaan giginya yang berjejal dan menganggu penampilannya. Diagnosis kasus adalah maloklusi dentoalveolar kelas I angle disertai crossbite gigi 12 dan 21, crowding anterior rahang atas dengan profil muka cembung, garis median tidak sesuai dan tidak disertai gangguan TMJ. Rencana perawatan menggunakan quad helix dan tanggul gigitan posterior kemudian dilanjutkan dengan perawatan ortodontik cekat. Tujuan artikel ini adalah menyajikan perawatan crossbite anterior dengan menggunakan kombinasi quad helix dan tanggul gigitan posterior. Pasien dirawat menggunakan tanggul gigitan komposit posterior pada permukaan oklusal gigi 16, 26 dan quad helix yang disolder pada molar band dan disementasi di molar band pada gigi 16 dan 26 kemudian pasien diinstruksikan untuk kontrol setiap dua minggu satu kali kunjungan untuk aktivasi quad helix. Setelah perawatan aktif 3 bulan crossbite anterior telah terkoreksi. Alat ditinggalkan di dalam mulut dalam keadaan pasif selama 3 bulan sebagai retensi. Dapat ditarik kesimpulan bahwa perawatan crossbite dengan kombinasi quad helix dan tanggul gigitan posterior efektif dalam mengoreksi crossbite anterior pada remaja.
\end{abstract}

Kata Kunci: crossbite anterior, quadhelix, tanggul gigitan posterior

\begin{abstract}
Combination quad helix and bite riser posterior for anterior crossbite treatment. Anterior crossbite treatment can be done with the appliances either by removable appliances or fixed appliances. One fixed appliance that can be used in the treatment of anterior crossbite is a quad helix with a combination of bite raiser posterior. It is the preferred appliance for correction of maxillary dental constriction in a preadolescent child. Quad helix is activated by widening the anterior or posterior helices. An 11-year-old female patient referred to the clinic with a problem of crowding teeth that affected her appearance. The diagnosis for her case was malocclusions dentoalveolar class I angle along with anterior crossbite 12 and 21, anterior crowding maxilla with convex face profile, shifted median line, and no TMJ disorder. The treatment plan used a quad helix and bite riser posterior followed by a fixed orthodontic treatment. The aim of this study was to correct the anterior crossbite using a combination of a quad helix and bite raiser posterior. The patient was treated using composite bite raiser posterior on the occlusal surface of 16.26, and quad helix soldered to bands and cemented on 16 and 26. The patient was instructed to get her teeth controlled every two week to activate quad helix. After 3 months of active treatment, anterior crossbite was corrected. The appliance was left passively in place for 3 months as retention. The study concluded that crossbite treatment with a combination of a quad helix and bite riser was effective in correcting anterior crossbite in adolescents.
\end{abstract}

Keywords: anterior crossbite, quad helix, posterior bite riser

\section{PENDAHULUAN}

Crossbite anterior didefinisikan sebagai kondisi gigi anterior rahang atas berada pada posisi

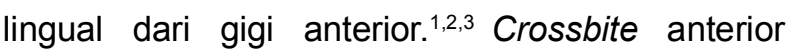
dapat disebabkan oleh beberapa faktor seperti arah erupsi insisif anterior maksila ke arah lingual, post operasi celah bibir, trauma gigi insisif yang menyebabkan perpindahan benih gigi permanen ke arah lingual, supernumerer gigi anterior, over retensi gigi sulung, odontoma, gigi berjejal regio insisif, panjang lengkung yang tidak adekuat atau kebiasaan menggigit bibir atas. ${ }^{1}$

Perawatan untuk mengkoreksi crossbite anterior dental dapat dimulai pada periode geligi campuran. Alat yang dapat digunakan seperti tongue blade, reverse stainless steel crown, 
Hawley appliance dengan z spring dan bonded resin-composite slope. Tongue blade hanya dapat digunakan bila pasien kooperatif tetapi alat ini tidak terkontrol dan arah daya yang diaplikasikan tidak ada. Reverse stainless steel crown merupakan alat yang dapat digunakan untuk terapi crossbite anterior tetapi memiliki kerugian yaitu tidak estetik dan pergerakannya hanya sebatas pergerakan 1 gigi. Hawley appliance juga membutuhkan pasien yang kooperatif dan supervisi orangtua. ${ }^{4}$ Alat lainnya yang dapat digunakan adalah quad helix.

Quad helix merupakan alat yang dapat digunakan untuk konstriksi dental di maksila pada masa remaja. Daya gerak yang baik didapat ketika quad helix dilebarkan adalah sebesar 3-8 mm. Keunggulan alat ini yaitu dapat diaktivasi secara intra oral maupun ekstra oral. Untuk mencegah iritasi jaringan, quad helix harus ditempatkan 1 sampai $1,5 \mathrm{~mm}$ menjauhi jaringan lunak palatal. Alat ini dapat menggerakkan gigi sulung dan gigi permanen dan dapat meningkatkan ekspansi dari sutura midpalatal, khususnya pada pasien usia muda, oleh karena itu, koreksi yang dihasilkan merupakan kombinasi dari perubahan dental dan skeletal walaupun hanya membutuhkan perubahan skeletal saja ataupun dental saja. Hal ini tidak memiliki konsekuensi dan tidak menimbulkan perbedaan dengan perawatan serupa ataupun teknik retensinya. ${ }^{5,6}$ Untuk membuka gigitan pada terapi crossbite, dapat digunakan alat bantu berupa tanggul gigitan.

Tanggul gigitan digunakan pada awal perawatan crossbite. ${ }^{7}$ Menurut Proffit, 2010 , koreksi crossbite anterior dental memerlukan pembukaan ruangan yang cukup kemudian membawa gigi yang mengalami crossbite melewati oklusi ke posisi yang tepat. ${ }^{4,6}$ Pilihan membuka gigitan pada perawatan crossbite baik anterior maupun posterior memerlukan alat, salah satunya tanggul gigitan. Tanggul gigitan bisa berupa bite plane pada akrilik atau pada kasus ini menggunakan komposit yang diaplikasikan pada gigi posterior rahang atas untuk membuka gigitan sebanyak 1 sampai $2 \mathrm{~mm}$ sehingga dapat mengembalikan posisi gigi yang mengalami crossbite ke dalam lengkung normalnya. Perawatan crossbite dengan tanggul gigitan biasanya dikombinasikan dengan alat lepasan. ${ }^{8}$

Tujuan artikel ini adalah membahas cara perawatan crossbite anterior dengan kombinasi quad helix dan tanggul gigitan posterior dilanjutkan dengan perawatan ortodonti cekat. Kasus ini telah

disetujui oleh orang tua pasien untuk dipublikasikan bagi kepentingan ilmu pengetahuan.

\section{METODE}

Seorang pasien perempuan berusia 11 tahun diantar orang tuanya dengan keluhan gigi rahang atas berjejal dan tumpang tindih. Pasien memiliki kebiasaan mengedot ketika kecil dan berhenti di usia 5 tahun. Orang tua pasien merasa penampilan anaknya terganggu sehingga ingin dirawat dengan ortodontik cekat. Sebelum dilakukan tindakan pasien mengisi dan menandatangani informed consent dan setuju dilakukan tindakan dan setuju kasusnya dipublikasikan. Pada pemeriksaan ekstra oral terlihat tipe muka normal, cembung, bibir normal dan lip seal positif (Gambar 1). Intra oral ditemukan maloklusi kelas I Angle dengan adanya crossbite anterior gigi 12, 21 dan garis median rahang bawah bergeser ke kanan sebanyak $2 \mathrm{~mm}$ (Gambar 2). Pasien berada pada periode gigi permanen. 


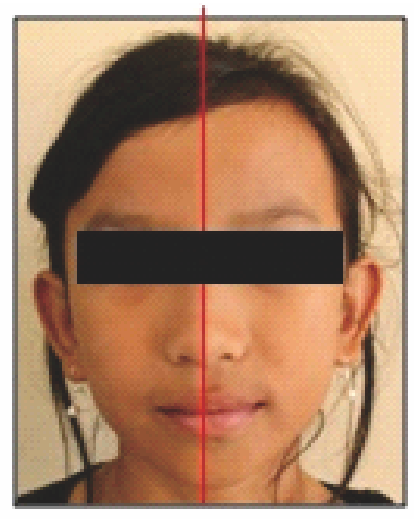

(A)

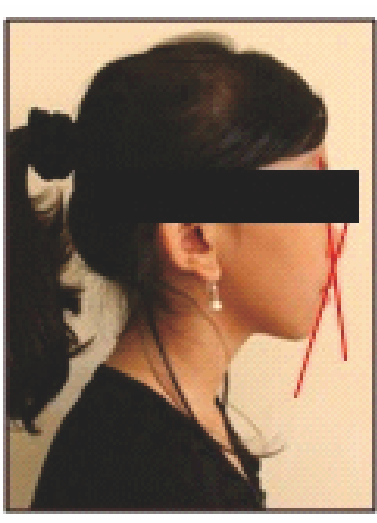

(B)

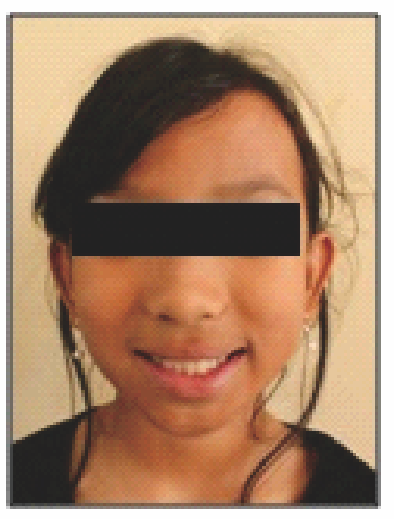

(C)

Gambar 1.Pemeriksaan ekstra oral menunjukkan tipe muka normal (A) dengan profil cembung (B) bibir dan lip seal positif (C)
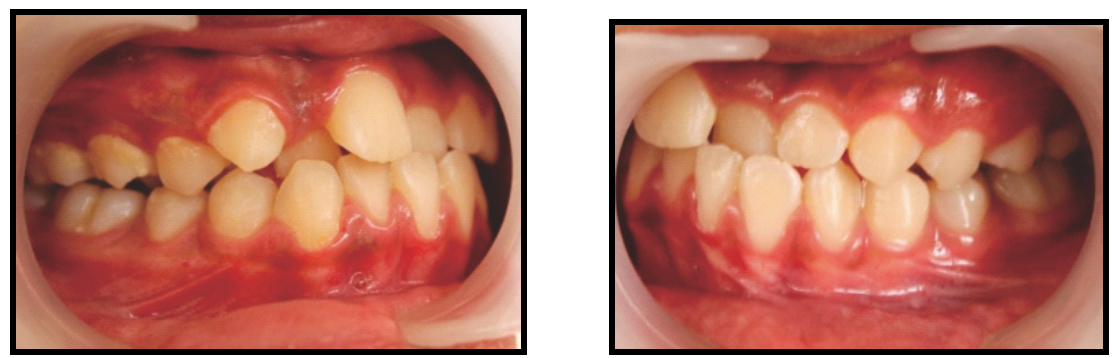

(A)

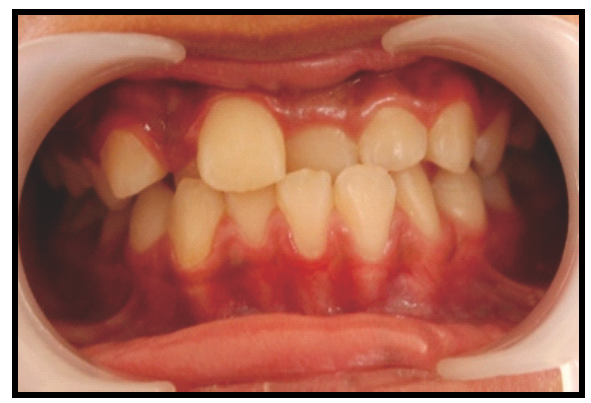

(B)

Gambar 2.Pemeriksaan intra oral menunjukkan Maloklusi Angle kelas 1 (A) dengan Crossbite Anterior (B)

Setelah dilakukan pencetakan dan analisis model didapat hasil Arch Length Discrepancy (ALD) rahang atas kekurangan ruangan dental 4 $\mathrm{mm}$ dan rahang bawah kekurangan ruangan dental $1 \mathrm{~mm}$. Perhitungan indeks howes didapat angka $44,7 \%$ yang artinya rahang atas cukup aman untuk diekspansi.

Analisis panoramik memperlihatkan keadaan normal, bentuk dan tinggi kondilus normal, sinus nasalis dan maksilaris normal. Analisis sefalometri dengan steiner tidak ada kelainan (SNA $79^{\circ}$, SNB $78^{\circ}$, ANB $1^{\circ}$, I-NA24 $4^{\circ}$, I-NB $32^{\circ}$. Analisis downs didapat bidang mandibula $33^{\circ}$ menunjukkan high Angle, sumbu $Y 69^{\circ}$ menunjukkan pola pertumbuhan mandibula lebih ke posterior, bidang oklusal $20^{\circ}$ menunjukkan bidang oklusal curam, sudut antar insisif $126^{\circ}$ menunjukkan insisif protrusi,sudut insisif rahang bawah terhadap bidang mandibula $+7^{\circ}$ menunjukkan labioversi dan insisif rahang bawah terhadap bidang oklusal $21^{\circ}$ menunjukkan tidak normal (Gambar 3 dan 4). Hasil analisis wits didapat jarak titik $A$ ke oklusal dan titik $B$ ke oklusal 
adalah $2 \mathrm{~mm}$ memperlihatkan bahwa pasien ini memiliki skeletal kelas I.

Dari seluruh analisis yang telah dilakukan dapat ditarik diagnosis pasien yaitu maloklusi dentoalveolar kelas I angle disertai crossbite gigi 12 dan 21, crowding anterior rahang atas dengan profil muka cembung, garis median tidak sesuai dan tidak disertai gangguan TMJ dengan etiologi ketidaksesuaian panjang lengkung gigi dan panjang lengkung rahang. Rencana perawatan pada pasien ini adalah penggunaan kombinasi quad helix untuk mengekspansi rahang atas dan tanggul gigitan posterior untuk membuka gigitan di anterior setelah crossbite terkoreksi dapat dilanjutkan dengan perawatan ortodonti cekat.

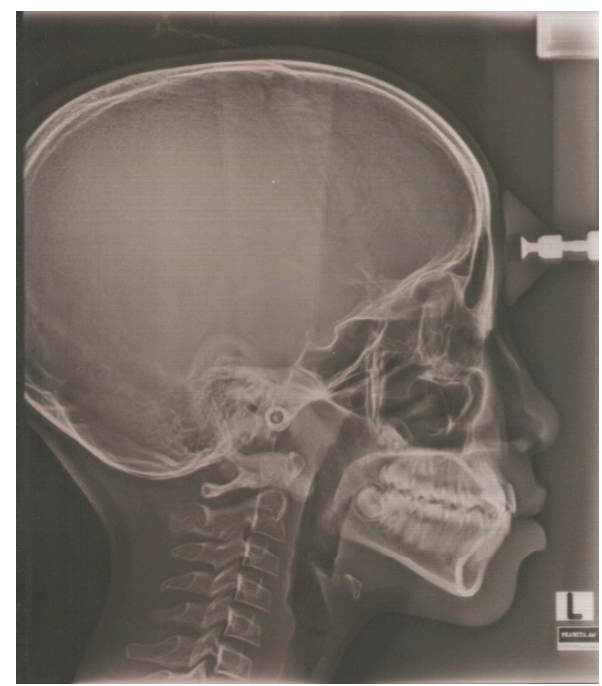

Gambar 3. Rontgen Sefalometri menampilkan gambaran rontgen lateral dari pasien

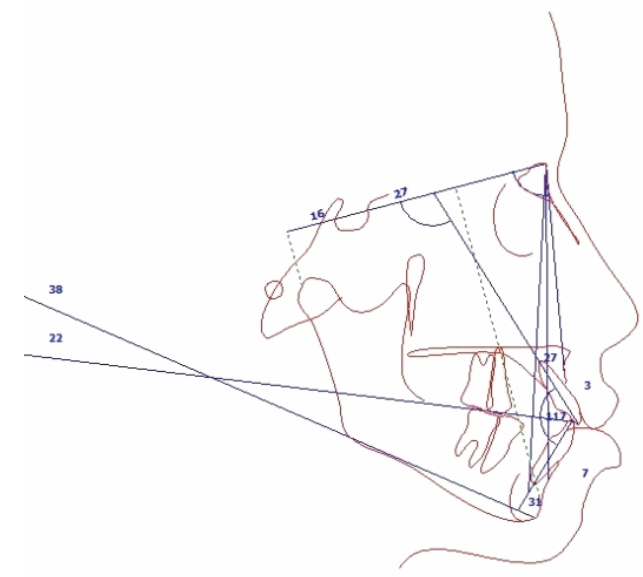

(A) Analisis Steiner

\section{HASIL}

Pasien dirawat dengan quad helix dengan sementasi molar band dengan quad helix pada gigi 16 dan 26 kemudian pasien diinstruksikan untuk kontrol setiap dua minggu satu kali kunjungan untuk aktivasi quad helix (Gambar 5). Setelah perawatan aktif selama 3 bulan crossbite anterior telah terkoreksi. Alat dipasang di dalam mulut dalam keadaan pasif selama 3 bulan sebagai retensi dan dilanjutkan dengan perawatan ortodontik cekat untuk memperbaiki susunan gigi geligi rahang atas dan rahang bawah bawah serta hubungan oklusi rahang atas dan rahang bawah (Gambar 6).

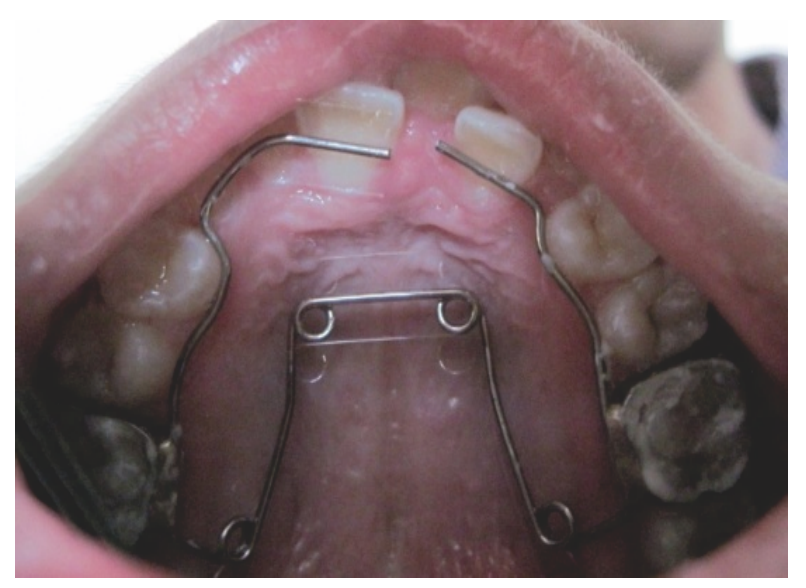

Gambar 5. Pemasangan quad helix di maksila

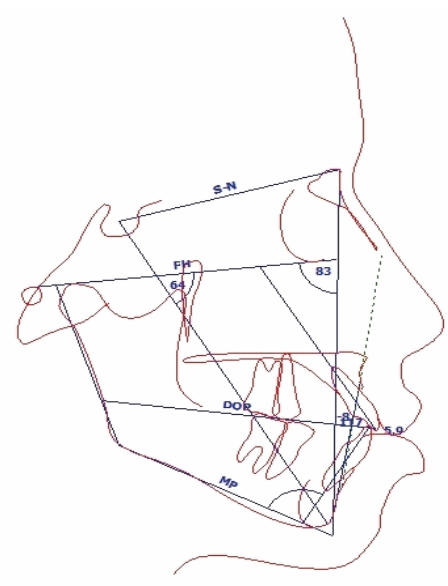

(B) Analisis Downs

Gambar 4. Analisis Sefalometri Steiner menunjukkan tidak ada kelainan (A) dan Analisis Downs menunjukkan keadaan tidak normal (B) 


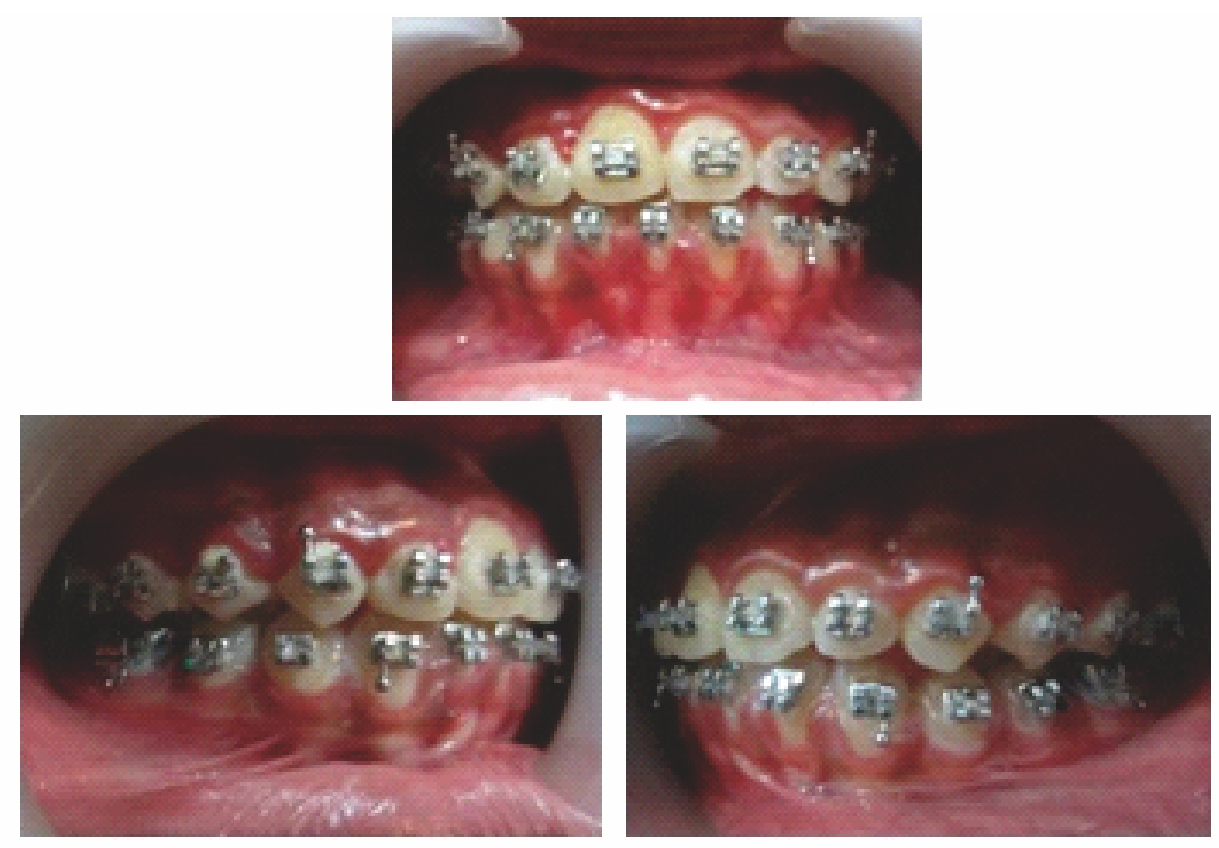

(A)

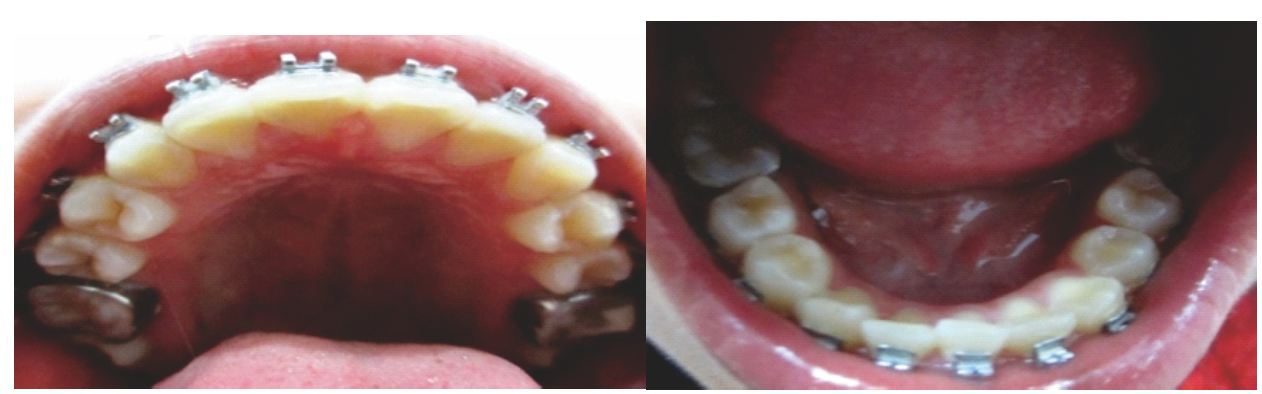

(B)

Gambar 6. Gambaran setelah perawatan ortodontik cekat selama 6 bulan, terlihat susunan gigi telah rapi (A) Pandangan labial, kiri dan kanan (B) Gambaran Rahang Atas dan Rahang Bawah

\section{PEMBAHASAN}

Inti dari terapi crossbite adalah membuka gigitan dan membawa gigi yang mengalami crossbite melewati bidang oklusi ke posisi yang tepat. Tanggul gigitan dapat digunakan bila terdapat cukup ruangan untuk proklinasi gigi anterior. ${ }^{8}$ Alat yang digunakan untuk membuka gigitan adalah dengan tanggul gigitan posterior. Bila crossbite terjadi pada saat gigi masih erupsi dan masih terdapat ruangan yang cukup, pilihan perawatan bisa dengan menggunakan tongue blade. Pilihan alat yang digunakan pada kasus ini adalah bite riser posterior dengan menggunakan komposit yang diaplikasikan pada gigi posterior rahang atas dan quad helix.
Quad helix merupakan alat yang dapat digunakan untuk konstriksi dental di maksila pada masa remaja. Penggunaan alat ini sederhana dan mudah digunakan tetapi membutuhkan kerjasama pasien. Pilihan perawatan lain adalah dengan rapid maxillary expansion. Menurut Vasant (2009), quad helix menghasilkan pergerakan skeletal lebih baik dibandingkan rapid palatal expansion. ${ }^{9}$

Quad helix diaktivasi dengan melebarkan helix. Melebarkan helix di bagian anterior akan menghasilkan pergerakan gigi di posterior sedangkan pergerakan gigi di anterior dihasilkan dengan cara melebarkan helix di posterior. Alat ini menghasilkan level daya yang dapat menggerakkan gigi bila dibuka 3 sampai $4 \mathrm{~mm}$ lebih lebar dari lebar 
pasif dan harus diaktifkan pada dimensi tersebut sebelum diinsersikan. ${ }^{6}$

Ekspansi harus dilanjutkan dengan jarak $2 \mathrm{~mm}$ per bulan (pergerakan gigi $1 \mathrm{~mm}$ pada setiap sisi) sampai crossbite sedikit overkoreksi. Dengan kata lain, puncak bonjol lingual dari gigi maksila harus beroklusi dengan puncak bonjol bukal dari molar mandibula pada akhir masa aktif perawatan. Pengaturan alat intraoral dapat menghasilkan perubahan yang tidak diinginkan, oleh karena itu pengambilan dan resementasi quad helix direkomendasikan untuk dilakukan di setiap kunjungan perawatan. Crossbite posterior membutuhkan 2 sampai 3 bulan perawatan aktif dan 3 bulan masa retensi (alat quad helix ditinggalkan dalam keadaan aktif didalam mulut) untuk stabilisasi. ${ }^{6}$ Relaps pada perawatan crossbite seringkali terjadi pada 2 tahun pertama setelah perawatan. ${ }^{10}$ MenurutWiedel (2015), stabilisasiyang didapat setelah perawatan dengan menggunakan quad helix lebih stabil dibandingkan dengan alat lepasan berupa plat dan skrup ekspansi. ${ }^{10}$

Evaluasi hasil perawatan setelah 2 tahun setelah alat dilepas, tidak terjadi relaps dan kontak oklusi dalam keadaan baik.

\section{KESIMPULAN}

Perawatan crossbite dengan kombinasi quad helix dan tanggul gigitan posterior efektif dalam mengoreksi crossbite anterior pada usia remaja, akan tetapi perlu dikaji alternative alat lain yang dapat mengoreksi crossbite sehingga hasil perawatan lebih optimal.

\section{DAFTAR PUSTAKA}

1. Bayrak, Tunc. Treatment of anterior dental crossbite using bonded resin-composite slopes: case reports. Eur J Dent. 2008 Oct; 2: $303-306$.
2. Yaseen SM, Acharya R. Hexa helix modified quad helix appliance to correct anterior and posterior crossbites in mixed dentition. Hindawi Publishing Corporation. 2012; 2012(2012): 1 5. Article ID 860385.

3. Ulusoy AT, Bodrumlu EH. Management of anterior dental crossbite with removable appliance. Contemporary Clinical Dentistry. 2013 Apr-Jun; 4(2): 223 - 226.

4. Prakash P, Durgesh BH. Anterior crossbite correction in early mixed dentition period using catlan's appliance: a case report. ISRN Dent. 2010; 2011: 1 - 4. Article ID 298931.

5. Ashith MV. Modified quad helix: a case report. International Journal Scientific Study. 2015; 2(10): $158-162$.

6. Proffit WR, Fields HW, Sarver DM. Contemporary orthodontics. United States: Elsevier; 2010 Section V. 433 - 436.

7. Guray, Enis. Temporary bite opening with guray bite raiser. Florida: Ortho Technology; 2012. 1 - 8 .

8. Jirgensone I, Liepa A, Abeltins A. Anterior crossbite correction in primary and mixed dentition with removable inclined plane (bruckl appliance). Stomatoligija: Baltic Dental and Maxillofacial Journal. 2008; 10: 140 - 144.

9. Vasant MR, Menon CS, Kannan MS. Maxillary expansion in cleft lip and palate using quad helix and rapid palatal expansion screw. MJAFI. 2009; 65(2): 150 - 153.

10. Wiedel AP, Bondemark L. Stability of anterior crossbite correction: a randomized controlled trial with a 2-year follow up. Angle Orthodontist. 2015; 85(2): 189 - 195. 